accepted for publication by

Peace and Conflict: Journal

of Peace Psychology on 04.01.2021

\title{
Radicalization and Deradicalization:
}

\section{A qualitative analysis of parallels in relevant risk factors and trigger factors}

\author{
Julia Reiter* https://orcid.org/0000-0002-7451-9441, \\ Bertjan Doosje** https://orcid.org/0000-0002-2479-5405 \\ \& Allard R. Feddes** https://orcid.org/0000-0002-3294-6242 \\ * University of Vienna \\ ** University of Amsterdam
}

Abstract word count: 107

Main text and references word count: 12802

Footnotes word count: 110

Number of tables and figures: 5 tables

Supplementary Online Materials: 3

Tables word count: 1107

Table notes word count: 357

Author note

Other parts of the data sets described in the present manuscript will be published in the IJCV (Reiter \& Doosje, 2020). We extend our deepest gratitude to Nadine Jukschat and her colleagues at the Criminological Research Institute of Lower Saxony (KfN e.V.) for conducting these interviews and providing us with the transcripts.

Correspondence concerning this article should be addressed to Julia Reiter, Faculty of Psychology, Department of Developmental and Educational Psychology, University of Vienna, Universitätsstraße 7, 1010 Vienna. E-mail: julia.reiter@univie.ac.at. 


\begin{abstract}
We analysed five narrative interviews with individuals who disengaged from Islamist extremist and Salafist ideologies in an early stage of radicalization (Study 1) and seven semi-structured expert interviews with employees of German deradicalization-programmes (Study 2) to explore which root factors are common to both radicalization and deradicalization and how they manifest. Employing a coding-reliability approach to Thematic Analyses, we constructed five themes central in radicalization and deradicalization, respectively. Parallels between radicalization and deradicalization (themes: social surroundings, exclusion vs. acceptance, social status, self-definition, structure / sense of purpose) as well as the specifics of our particular sample - female explorers of religious extremism - and implications for future research are discussed.
\end{abstract}

Keywords: radicalization, deradicalization, thematic analysis, social identity, disengagement

Public significance statement: Interview data from young adults who had explored religiously radicalized movements in the past (specifically, the Salafist movements in Germany, mainly the group around German public preacher Pierre Vogel) as well as from experts working in German deradicalization programmes are analysed. The most important factors influencing radicalization and deradicalization were related to social belonging and social identity. Preventative efforts should focus on social inclusion, countering discrimination and proactively working with youth to resolve identity crises. 


\section{Radicalization and Deradicalization:}

\section{A qualitative analysis of parallels in relevant risk factors and trigger factors}

To date, a substantial body of literature has been produced on the process of radicalization. To a lesser extent, the same has been undertaken for the processes of deradicalization and disengagement (Barrelle, 2014; Bubolz \& Simi, 2015; Doosje et al., 2016; Horgan et al., 2017; Winter \& Feixas, 2019), where disengagement describes the behavioural side and deradicalization the attitudinal side of distancing oneself from extremist ideologies and groups (Della Porta \& LaFree, 2012). Little focus has been placed on the relation between radicalization and deradicalization and how factors that play a key role in the former might influence the latter. Generally, some coherence is expected between the factors that played a part in a person's radicalization and deradicalization (cf. Barrelle, 2014; Sikkens et al., 2017; Winter \& Feixas, 2019), but comparative studies are scarce. This question is interesting because it speaks to the validity of inferences drawn from radicalization research to deradicalization. By extension, this is also of practical relevance: If there is high similarity between the factors relevant for radicalization and deradicalization, deradicalization counsellors are well-advised to explore their clients' radicalization history extensively. We approach this question using qualitative data from interviews with individuals who disengaged during the early stages of radicalization (Study 1) and expert interviews with employees of deradicalization programmes (Study 2).

\section{Root Factors}

Numerous factors have been identified which influence the process of radicalization. Sometimes these are discussed as root factors in a broad sense, while other authors draw distinctions between risk factors and trigger factors. Risk factors are persisting states resulting in general psychological strain which leaves the individual vulnerable to radicalizing influences, while trigger factors are conceptualized as discrete 
events which prompt or catalyse a transition from one stage of (de-)radicalization to another (Feddes et al., 2015). The same trigger factor can have radicalizing or deradicalizing effects, depending on other factors such as a person's motivational structure or their framing and appraisal of the event. By contrast, risk factors are not discrete events, but permanent states which build up their influence on the process (cf. Kruglanski \& Fisherman, 2009). Finally, in addition to risk factors and trigger factors, some studies investigate psychological motives of radicalization (Macdougall et al., 2018). Motives are distinct from these other root factors in that they are largely personalityinherent and stable over time and interact with other factors: The presence of other root factors can make a motive more salient, while strong motives also enhance sensitivity to certain, thematically related root factors.

The root factors which we identified - drawing on literature on risk factors, trigger factors, and psychological motives - and included in our coding system are discussed in the Methods section below. These factors are embedded in the process of radicalization and deradicalization.

\section{Radicalization and Deradicalization}

There is overall agreement that radicalization is a multiphasic, dynamic process, the course of which is influenced by root factors. The occurrence of trigger factors can prompt shifts between phases, while the presence of risk and protective factors can more generally speed up or slow down these movements. Exiting this process at any stage is referred to as deradicalization or disengagement, depending on whether attitudinal or behavioural change is central. With our data, we explore which root factors are common to both radicalization and deradicalization and how they manifest.

\section{Epistemological and Methodological Preface}

Qualitative methods exist within a framework of epistemology and methodology; the researcher's assumptions on what can be known and how research can produce 
this knowledge shape the choice of appropriate methods and the interpretation of results (Carter \& Little, 2007). It is important to explicate these assumptions because the key criterion for a qualitative study's quality is the internal consistency of epistemology, methodology, choice of method and presentation of results (Carter \& Little, 2007).

We assume that, certain distortions such as hindsight bias and social desirability bias aside, people's true attitudes, experiences and opinions can be accessed through interviews. The study was not conducted with a constructivist approach, but with the participant as the subject from whom information is obtained. Although our study is not suitable for model testing (due to sample restrictions) and remains explorative, every step of the process was guided by theory. Data collection differed between studies 1 and 2 (details below), but for data analysis, a set of codes was constructed based on an extensive literature review concerning the process of radicalization and deradicalization and its root factors. In doing so, we paid attention to include empirical as well as major theoretical works. The literature review phase stopped when we reached saturation, i.e. we could no longer find articles adding new factors to our framework. The initial, purely theory-based codebook was expanded with a grounded theory approach (see below). After all interviews had been coded, a second coder was instructed with these definitions to code two randomly chosen interviews (one from each study). Differences between the coders were discussed and interrater agreement was determined. This is due to a methodological approach which expects to produce at least a shared interpretation marked by replicability.

While this approach is at odds with more constructivist approaches to qualitative research, it suited our interest: We had a theoretical model which guided our expectations and wanted to see how well this analytical framework would fit the set of field data we managed to gather. 


\section{Method}

In Study 1, we analysed data collected from five interviewees who had passed through the early stages of radicalization (explorative behaviour, group membership) and then disengaged or deradicalized. In Study 2, we analysed expert-interviews with seven consultants from different German exit-programmes which support members of radical groups who are willing to disengage. Approval was granted by the ethics committee of the University of Göttingen.

\section{Method Study 1}

\section{Sample}

Data were provided for secondary analysis by the Criminological Research Institute of Lower Saxony in the form of the anonymized transcripts of five narrative interviews conducted with Muslims who self-identified as devout and who had, in the past, explored radical ideologies, but not moved on to phases of serious involvement. Participants had been recruited via Facebook and Instagram and self-selected for participation (see Table 1 for more information about the interviewees). The interviews passed on to us were part of a sample of 12 narrative interviews which were part of the Research Center's more general sociological research on Muslim identity formation. Therefore, these interviews were not tailored to our research. The five interviews passed on to us were selected by the researcher at the Research Center who was in charge of their sociological study based on who had mentioned by name public figures who are considered to be radical Islamist preachers and/or part of the Salafist scene in Germany and described involvement with them (such as engaging with their videos, attending meetings). The public figure who was decisive for the selection of several interviews in this sample was Pierre Vogel, public preacher and most famous member of the Salafist association EZP (German acronym for "invitation to paradise"), 
a group continuously monitored by the Federal Office for the Protection of the Constitution.

As such, Study 1 was based on a convenience sample. Out of the population of interest - people who had at some point been engaged in the radicalization process, e.g. by being in touch with radical groups or seeking out extremist content online, but had since disengaged/deradicalized - this was a very particular subsample: only Islamist/Salafist radicalization was represented and the sample was predominantly female. Moreover, self-selection bias has skewed this sample towards particularly open and self-reflective individuals.

\section{Interviews}

The interviews had been conducted in different cities in Lower Saxony (Germany). The interviews opened with a general narrative prompt inviting participants to share their experiences with finding their Muslim identity; subsequently, the interviewees talked freely, without interruption, except for clarification or elaboration on certain aspects, so as not to cut the narrative short. The narrative interviews were conducted by a sociologist who is very familiar with this approach. One possible limitation in this study is that we did not conduct these interviews ourselves, and due to this as well as due to the open format of the narrative interview, they were not as intentionally focused

on our research questions as the semi-structured interviews in Study 2. Nevertheless, the overall topic of the interviews was the same and examination of the data proved them to be well-suited for the purposes of our study.

\section{Analysis}

Data were analysed using a theory-based coding scheme. An original set of codes was developed within a theoretical framework prior to the first analysis of the data and subsequently built on inductively. 
To analyse the texts, we took a "coding reliability" type of approach to Thematic Analyses (Braun \& Clarke, 2016): The coding scheme included definitions and establishing inter-coder agreement was part of the process. Two interviews were first chosen at random for an initial reading. Thereafter, an initial set of codes (discussed in more detail below) was created based on a previous review of current literature. They were then applied to one of the initial interviews as well as a newly selected third one. During this step, other recurring topics were identified as relevant to the research questions and added as codes. After the authors agreed that theoretical saturation was reached, the resulting final coding scheme was applied to the entire data set. Inter-coder agreement was assessed on a sub-sample (see below).

Coding Scheme. The original codebook contained sixteen trigger factors, seven risk factors and seven psychological motives derived from literature review; ten codes were added in the iterative steps between initial, theory-based codebook and theoretical saturation. The minimal coding unit was a sentence. If the same topic was expressed in more than one sentence without interruption by another topic, the entire coherent segment was marked with the corresponding code. The final, complete coding system, including definitions and examples, can be found in Supplementary Online Materials, supplement S1.

The first group of root factors derived from literature review were trigger factors. Trigger factors are events that can occur in the immediate domestic environment, for example in the form of confrontations with death (Kruglanski et al., 2009), domestic problems (Sikkens et al., 2017), the loss of educational or professional perspectives (Feddes et al., 2015; Özerdem \& Podder, 2011), or detention and imprisonment (Kruglanski et al., 2015). They can also be facets of intergroup interactions, such as direct experiences of discrimination (Frounfelker et al., 2019; King \& Taylor, 2011), racism or exclusion, or negative experiences with public authorities (Frounfelker et al., 
2019), or they can be reflective of the social environment in general, such as actively cutting social bonds (Doosje et al., 2016) which can result more generally in social alienation (Bélanger et al., 2019), establishing contact with radical groups or individuals, and participating radical group activities such as training camps. Finally, there are possible trigger factors which are more abstract than personal, such as confrontations with propaganda (Baugut \& Neumann, 2019; Baugut \& Neumann, 2020), perceived attacks on the ingroup, and governmental policies targeting the ingroup or radicalization (Feddes et al., 2015). Finally, a key trigger factor for deradicalization and disengagement (Barrelle, 2014; Bjørgo, 2011) is disillusionment. The ultimate moment of disillusionment has been described as a turning point in empirical studies of deradicalization (e.g. Horgan et al., 2017). The perceived costs and benefits of staying versus leaving may change gradually (Horgan et al., 2017) until action in the form of disengagement is triggered by disillusionment (Bjørgo, 2002). Disillusionment may relate to the ideology itself (i.e. losing one's conviction of the ideology and its system of postulates) or to experiences with the social and practical components of a radical group or movement (i.e. losing the illusion that membership in the radical movement will fulfil one’s needs) (Bjørgo, 2002; Bubolz \& Simi, 2015).

Feddes et al. (2015) theorize about a moderation of the effects of these trigger factors by sociodemographic variables and psychological motives. These psychological motives form the second group of root factors included in the coding system: The motives which have been identified as pivotal in the radicalization process are the need for social belonging (Harris et al., 2014; Macdougall et al., 2018), emotional uncertainty (Doosje et al., 2013), need for existential meaning (Cottee \& Hayward, 2011; McBride, 2011), need for status (Webber et al., 2018; Webber \& Kruglanski, 2018), need for sensation (Nussio, 2017; Schumpe et al., 2018) and need for justice (van den Bos, 
2018; van den Bos, 2020). Research concerning these motives as a coherent system and possible moderations is still in its early stages (Macdougall et al., 2018).

The final group of root factors identified and included in the coding system are risk factors. Literature on general risk factors of radicalization is, by contrast, more systematically advanced. Doosje et al. $(2012,2013)$ test a model including six factors with robust results: Firstly, relative deprivation (both individual and collective) (see also Borum, 2003; King \& Taylor, 2011; Macdougall et al., 2018; Moghaddam, 2005) describes a perception that the individual or the entire ingroup are at a symbolic or material disadvantage compared to an outgroup. Secondly, the degree of ingroup identification determines to what extent one feels that belonging to one's ingroup is central to one's identity. It has been demonstrated to relate to uncertainty (Reid \& Hogg, 2005) as well as intergroup bias (Castano et al., 2002). Thirdly, intergroup anxiety is an emotional response to perceived intergroup conflicts and their consequences (Stephan \& Stephan, 1985; Turner et al., 2007; Turner et al., 2008). Fourthly, perceived threat pertains to symbols representative of the ingroup or to the ingroup itself in economic or physical terms (e.g., the looming threat of poverty or intergroup violence). Such threat perceptions can increase readiness to act in perceived self-defence (McCauley \& Moskalenko, 2008). Personal uncertainty pertains to identity and circumstances in life. Radical ideology presents an opportunity for easy uncertainty reduction by providing simple answers to complicated questions. Finally, perceived injustice, within the context of intergroup relations, is the perception that a group the individual relates to is being treated unfairly and the individual should be doing something about it (Van den Bos, 2018).

The factors added during the iterative expansion of the coding system were a harmful social environment, mental health issues, positive social influence, critical thinking, perspective taking, positive attitudes towards the democratic / legal system, 
commitment, responsibility, reactance, and experiences of violence (see supplement S1). Not all codes were applied frequently or fit into coherent themes; some only played a role for one person and would therefore be more central in an individual case study. Since we focused on themes that could be constructed across the whole collected data set with reasonable consistency, not all codes are mentioned in the analyses.

Inter-Rater Agreement. After all interviews had been coded by the first author (Coder $A)$, an external fellow researcher (Coder $B$ ) received thorough coding training by $A$ and coded one of the interviews. The training involved a comprehensive instructional document including code definitions and coding rules and a conversation to clear up any further questions. Basic coding rules included that it was possible and sometimes necessary to apply multiple codes to the same data item, that codes were meant to be applied generously (i.e. including the context of a particular event if necessary), and that most codes could be applied both in the positive and negative sense (i.e. to mark the presence or explicit absence or opposite of the code; a difference which was considered later during analyses).

As there were five interviews (10.9 hours in total), the interview chosen for double-coding by a random number generator (S1P4, 2.43 hours) made up $22.29 \%$ of the data set (Note: An S stands for Study and P stands for Participant). After B had finished coding this interview, the initial level of inter-rater agreement was established. Agreement was defined as any instance of the same code being applied by both coders to a content-wise coherent segment. Calculation of any reliability index requires data to be pre-divided into a fixed number of units, resulting in a number of data units on which raters agreed and disagreed, respectively. In our study, raters created the data units while coding. Thus, the data to which no codes were applied remained undivided into units - we can count the units on which the raters agreed, but not those on which they 
disagreed. Consequently, our evaluation of inter-rater agreement is limited to the percentage of overlap.

$A$ and $B$ then discussed all instances of disagreement together in order to determine the cause of the disagreement and whether it could be resolved. B was instructed beforehand that for each instance of disagreement, the possible outcomes were resolution in favour of $A$, resolution in favour of $B$, or non-resolution of the disagreement. The amount of inter-rater agreement was then re-assessed. Table 2 presents the resulting overlap in percent before and after discussion. Of the conflicts that were resolved, $63 \%$ were resolved in favour of coder $A, 33 \%$ in favour of coder B, and $4 \%$ found another resolution (see Supplement S2). Considerable improvement in inter-coder overlap post discussion indicates the overall good reliability of the coding system; pre-discussion discrepancies were mostly due to simple lapses of concentration caused by the large number of codes or by uncertainty resulting from the occasional vagueness of the data material. Overlap remained low for the codes policies aimed at the ingroup (50\%), meeting a radical person (33,33 \%) and relatively low for experiences of discrimination (75\%).

\section{Method Study 2}

\section{Sample}

We conducted seven semi-structured expert-interviews. The target group were consultants at German state- or privately-run exit-programmes $(n=6$ and $n=1$, respectively), aimed at helping individuals to exit extreme groups. We contacted all staterun programs and the larger privately-run programs we could find and invited them to participate; interviews were conducted with volunteers in Bavaria, North Rhine-Westphalia and Thuringia.

We were interested in the perspectives of professionals who worked directly with radicalized individuals seeking help to exit their radical group. We aimed to include 
participants working with different ideological backgrounds of radicalization. In the context of Germany, the largest (i.e. most salient and most common) types of extremism are radical Islamism/Salafism and right-wing extremism. Most programs focus on these two ideologies, while also attending to left-wing extremism and purpose-specific militant groups, such as the PKK (Kurdistan's Workers Party), on the side. Similarities between religious and political radicalization have been found in terms of risk factors (Doosje et al., 2012; Doosje et al., 2013; Schils \& Verhage, 2017), individual motivations (Webber \& Kruglanski, 2018) and factors leading to disengagement and deradicalization (Barrelle, 2014; Harris et al., 2017; Webber \& Kruglanski, 2018). Hence, we were interested in exploring various ideologies together instead of selecting only political or religious extremist ideologies.

Nineteen state-run and privately-run exit-programmes were invited to participate in expert interviews. The participants who responded positively to this invitation were interviewed face to face at their own offices during June 2018, after which the recorded interviews were transcribed. Table 3 presents a descriptive overview of the sample.

\section{Interviews}

We conducted semi-structured interviews; guiding questions (see Supplementary Online Materials, supplement S3) were developed based on the same literature review as the codebook and the findings from Study 1 . The interview consisted of an introductory part (own professional background, daily routines at work), a part about radicalization, another about deradicalization (during both: recognition of different types, examples), and a final concluding part, in which interviewees could make concluding remarks, add information or ask questions. The parts about radicalization and deradicalization followed an explorative logic: First, interviewees were prompted with an open-ended question to state which factors, in their opinion, posed a risk for radicalization, facilitated deradicalization, and which events they had observed to trigger 
concrete steps in the (de-)radicalization process. Once they had finished talking - uninterrupted by the interviewer except for clarifications - the interviewer specifically inquired about whichever factors from the theoretical framework they had not mentioned yet.

\section{Analysis}

The interviews were thereafter transcribed using the software f4transkript according to standard transcription rules based on Fuß and Karbach (2014) and checked against the original sound recordings for accuracy. The method of analysis and coding procedure were analogous to Study 1.

The order in which the interviews were coded was determined by a random number generator. As there were seven interviews $(9,60$ hours total), the interview randomly chosen for double-coding (S2P4, 1,55 hours) made up 16,15\% of the data set. Table 4 presents the resulting overlap in percent before and after discussion. Of the resolved conflicts, $58 \%$ were resolved in favour of coder A, $32 \%$ in favour of coder B and $10 \%$ were resolved otherwise (Supplement S2). The substantial rise in agreement after discussion paralleled that in Study 1; however, agreement remained low for joining a radical group and meeting a radical person. While clearly distinct in theory, the lines blur in practice. Frequently, both coders had marked the same sections of the text with either one of these codes because in the interviewee's account, it was not clear whether the person had joined a coherent group or was just loosely meeting with some people.

In addition to the rise in inter-coder agreement post discussion in both studies, pre-discussion agreement was also higher in Study 2 for half of the codes (a total of 18 codes were used in both studies and thus allowed for this comparison), indicating learning effects during coding. Finally, the interviewees from Study 2 were provided 
with their transcripts and a draft of the analyses and given an opportunity to respond and request corrections (which none of them did).

For Study 2, transcripts are available on motivated request to the first author; for Study 1, contact to the Research Center which provided us with the data will be gladly established upon request.

\section{Results}

Based on the frequency of and emphasis on different root factors, we constructed several themes. By constructed, we mean that we collated thematically related codes into larger constructs according to what made sense within the framework of existing psychological radicalization and deradicalization literature. We conclude that these themes are central to both radicalization and deradicalization in the views of both deradicalized individuals and experts. Therefore, we present a combined analysis of both studies. Table 5 summarizes the constructed themes.

\section{Themes in Radicalization:}

\section{Compensating for Domestic/Social Problems}

It was described as a common occurrence that individuals become vulnerable by severe domestic problems and problems in their social network - e.g. interview S2P2, line 122: "The risk factors I know of are almost exclusively social environment and family." All experts talked about either a peer group encouraging harmful behaviour and/or leading the individual into radicalization, or bad relationships with the parents. Being part of a radical group is one way to compensate for such issues, and radical groups - in particular, right-wing extremist groups - take advantage of this. For example, one expert describes his clients' strong desire for community and group affiliation:

Conditions [at home] are often precarious, (...) and the children who are socialised like this don't develop high self-esteem, and then they search for people they can hold on to, for group membership - they are accepted in those groups, they are 
treated well, and in the end that is what causes this strong connection to the rightwing scene. (S2P2, line 202)

Another expert emphasized the effects of lacking social support at home:

This has really been, throughout these seventeen and a half years, the central, recurrent theme in all deradicalized clients' biographies. It is very noticeable that, in most cases, a father figure was non-existent, and therefore they sought this father figure among older [group members], older like-minded people, just anyone who would take their hand and give them a feeling of security and 'I'll give your life direction'. That is the mark of all deradicalized biographies. (S2P7, line 187)

The expert placed strong emphasis on the role of lacking attachment figures in prompting radicalization; it was very salient to him that many of his clients sought to compensate a lack of close social bonds in their family elsewhere and radical groups took advantage of this desire by offering a group to bond with (in line with other findings on the role of domestic problems, Sikkens et al., 2017).

Other domestic problems described by deradicalized interviewees were mental health and drug abuse issues in family members, poverty, intra-familiar conflicts and custody battles. For example, male 21-year-old S1P4 (line 138), whose parents had been placed in investigative custody for allegedly smuggling drugs, stated: "Then they were in custody and from that moment on [...] I began to devote myself to Islam. I was 17 , and from that day on, I changed completely."

Both samples placed emphasis on the cutting of social bonds as a factor furthering radicalization where the process had already begun and hindering eventual disengagement and social reintegration. A participant in Study 1 had witnessed the progressive radicalization of an acquaintance who had eventually departed to join the ISIS fighters in Syria: “(...) when he began to become...I don't want to say extreme, but when he began to practise [his religion] more strictly, he...somehow, he became very withdrawn 
into himself (...)" (24-year-old Muslim convert S1P5, line 4282). Experts in Study 2 stressed that membership in a radical group typically entailed the gradual loss of all outside-contacts, which resulted in severe loneliness after disengagement (S2P7, line 70); leaving a radical group could mean leaving one's entire friend and support network, which is a fundamental obstacle.

\section{Experiencing and Compensating for Exclusion}

The need for social belonging was named as the central factor by different experts in Study 2 (particularly so for right-wing extremists). When this need is strong and a person is confronted with experiences of exclusion, be it on a personal or societal level, radical groups may offer an alternative way of fulfilling this need by joining them. The deradicalized interviewees reported experiences of discrimination and exclusion in a variety of contexts (school, family, close social circle, media and other official contexts). For example, female 21-year-old S1P1's vulnerability was heightened by constant and severe experiences of bullying during her school years.

Other interviewees described the effects of negative experiences with the authorities, although these descriptions were ambiguous: While the experts tended to view such experiences, e.g. confrontations with the police, as a deterrent from further engagement with radical ideologies, the deradicalized interviewees' descriptions of negative experiences with authorities portrayed them as trigger factors. For example, 21year-old Muslim convert S1P2 recalled her parents' custody battle and specifically how she was treated at Court as a traumatic childhood event. Government officials and representatives of the judicial system are representatives of the majority society, its rules and values. Therefore, while bullying in school or domestic problems can make someone feel a lack of connection to their immediate social surroundings, negative experiences with such authorities can prompt a feeling of social alienation (cf. Bélanger et al., 2019) and disconnectedness from said society. 
In relation to this, joining a radical group was cited as an important factor progressing radicalization or affirming one's commitment to an explored radical ideology in both studies. Our participants in Study 1 placed particular emphasis on social interaction in online spaces - several interviewees stressed the role of WhatsApp-groups.

Emphasis was placed in both studies on perceived attacks on the ingroup and governmental policies directed at the ingroup or at radicalization; both codes frequently overlapped with the codes discrimination, negative experiences with the authorities and with each other. Examples include 33 year old Muslim convert S1P3 presenting the case of her local government creating a comic intended to warn against Islamist radicalization and distributing it in schools; a comic that, to her, stigmatized and demonized all Muslims:

It was meant to warn children against the evil Islam, because this comic portrayed all fully veiled women as terrorists' wives or something and that's just not okay. Or all bearded men are sinister looking terrorists. That's not information or spreading awareness, that's pure propaganda. (S1P3, line 3677)

While this government measure was well-intentioned, this interviewee clearly perceived it as a strong ingroup attack and, as a result, her relationship with German society was negatively affected. Another example from the same interview was the case of a German law prohibiting women in face veils from driving cars.

There may not be a need to distinguish different levels and sources of discriminatory experiences in this context, because the large overlap of codes pertaining to this topic suggests that, whether discrimination occurs in the shape of one person harassing someone with racist slurs, or in the form of a government policy that systematically disadvantages an entire group and is perceived as an attack on the ingroup, it tends to make the person feel pushed out of majority society, which in turn causes them to seek group affiliation elsewhere. 


\section{Constructing Facets of Social Identity}

For some people, group membership does not only offer companionship, but an opportunity for self-definition. When struggling with identity issues, radical groups can be a key element in social identity construction. An example is provided by this expert, who describes the struggle of intersecting identities and trying to resolve this conflict by strengthening one's bond with one particular group identity:

The identity-type is certainly the largest portion. I think that's psychologically also due to puberty: Who am I, where am I from? For example, I have a Turkish background, l'm perceived as a Turkish person, but maybe I don't even speak the Turkish language and I try to define myself via religion, to find my identity (...). (S2P1, line 54)

We also found several segments coded as personal uncertainty (the second most frequently described motive) to be connected with questions of identity construction and the resolution of these questions provided by group affiliation; illustrated, for example, by this right-wing extremism expert's statement about gender and identity:

There's something very martial about the right-wing extremist scene, especially for the men. There's a huge obsession with masculinity. Everyone needs to have big [i.e., muscular] arms and so on. And for women, too, there are clear roles. And that offers a lot of security. (S2P3, line 92).

The expert described how strict and often traditional gender roles can form a potent mould to shape one's identity, which radical groups actively utilize to appeal to insecure potential new members. The descriptor "martial" links masculinity to violence, which is in line with previous statements made by another right-wing extremism expert about how much physical brutality occurs inside the right-wing extremist scene itself: 
We have a young woman who said: 'I have never encountered worse violence than internally, amongst members of the scene. Conflicts with political opponents, with foreigners, with left-wing extremists or with the police have never been brutal to the extent that I saw when two comrades were beating each other. (S2P7, line 128)

Violence has long taken a central role in the conceptualization of traditional masculinity (see, e.g., Morgan, 1987), which explains why the expert links "martial" and "masculine" with such ease in his observations. In a different strand of literature, it has also been suggested to conceptualize radicalization towards political violence as a process of martialization (Haggerty \& Bucerius, 2018).

Ingroup identification, building or affirming one's identity through membership of a particular social group, is a root factor that radical propaganda often seeks to appeal to, as described by an interviewee from Study 1 :

"[They] say 'Look, you're only being bullied here, just go to a Muslim country. Everything is great there and your children won't learn any infidel things from infidels, they'll learn Islam instead' and so on" (21-year-old German female with Turkish background S1P1, line 1842).

However, this can be a potent factor even without specifically targeted propaganda. For example, male interviewee S1P4, who grew up in a Muslim, German-Algerian household, describes his strong fascination with the status of being Muslim as a child in spite of his lack of concrete knowledge (line 67):

“(...) I always wanted to be Muslim. I don't know why, but when I was little, when I wasn't thinking about it as much yet, it wasn't a religion to me, it was more like...being Muslim was like being Spiderman or something, like a hero." 
He highlighted that the connection of group affiliation to social status was apparent to him, despite not really understanding what the group affiliation entailed. Affirming one's group identity often entails performing the identity in certain ritual ways, for example by following dress codes or other behavioural rules set by a group; as 33year-old convert S1P3 (line 1395) put it: "It's not like I have a lot of background knowledge about it. I just told myself, I'm a Muslim now, I want to wear a headscarf, because that's part of it." This description points to ritual performances for self-affirmation of her personal chosen faith. This indicates that there is overlap between ingroup identification and the theme of seeking structure (to be discussed below).

Among the experts, those working with former Islamist and PKK group members placed considerably more emphasis on ingroup identification than the experts on rightwing extremism. This is interesting considering ingroup identification has been linked to both right-wing extremism and Islamist extremism in existing literature (Doosje et al., 2012; Doosje et al., 2013).

\section{Improving Personal Status}

When someone perceives their status as low, e.g. due to lack of professional success, academic perspectives, precarious socio-economic status, radical groups can offer ways to enhance their status. Interviewees described a desire to feel important or powerful and how radical groups can offer to fulfil this desire - e.g. Muslim male interviewee S1P4: "[talking about a radical group] for me they were, whenever I saw them on the internet, they were stars, like celebrities. Then I really saw them in [city] and told them 'I want to join you'”.

As with previous motives, we observed agreement between people with own radicalization experiences and experts:

(...) many say that in the beginning, they were just tagging along, and then during the first crimes that are being committed, one just gets carried away, and 
you feel very powerful, you think 'wow, awesome, l'm a total hero now'. (S2P3, line 98)

This expert emphasized the strengthening of group ties as well as the boost in personal confidence and self-image which are intertwined with participating in delinquency together. Another expert added:

What I notice over and over again, and that's not necessarily independent from a quest for identity, is a quest for power. (...) This quest for power in the sense of 'I want to be looked up to and to be the one in charge'. That is, I think, a very important motivator - not for all of our clients, but for some. Especially those with narcissistic personality structures. (S2P1, line 54)

Achieving a position of power over others and validating one's identity through others' approval are often, as this expert described, two sides of the same medal.

Correspondingly, the loss and lack of academic or professional perspectives was one of the central trigger factors in both studies. Problems with school, higher education or finding a job were mainly reported as factors in early phases of radicalization, heightening vulnerability or encouraging exploration - e.g.:

I moved from there directly into my first own apartment in [city], and there I tried to find an apprenticeship position, which I didn't get back then. I wanted to train to be a doctor's assistant. Around that time, I met my first husband, got married, had children, goodbye apprenticeship. (female 33-year-old S1P3, line 637)

This interviewee, who eventually converted to Islam, described her difficulties on the labour market prior to and around the time of her first forays into religiosity. This relates to social identity construction in that academic and professional success are directly linked to societal standing. When these perspectives are missing, a person's perceived social status as well as their self-worth can suffer, both of which they may 
seek to compensate through other means (which participation in an extremist group can offer).

\section{Seeking out a Sense of Purpose, Existential Meaning}

When people search for a purpose in life, radical groups can offer clear and simple answers; the ideology they pursue typically presents a goal of fundamental importance and clear implications regarding how to live in accordance with that goal.

In line with this, some interviewees expressed a longing for clear and strict rules in their life, e.g. S1P3, a Muslim convert (line 1181): "In Islam, everything makes sense. Islam has an explanation for everything. (...) There's nothing, no questions, no essential questions are left unanswered. Everything is explained. And no other religion offers that."

This description showcases a strong desire for absolute answers and total clarity, containing elements of both the need for existential meaning and for uncertainty avoidance.

Need for justice was rarely mentioned in both our studies. This might reflect that this motive is generally minor compared to the previously described ones, or that people who are strongly motivated by a need for justice are less likely to deradicalize than those with other central motives. Either way, the need for justice aligns with the purpose-seeking theme, not least because of a substantial line of previous literature highlighting the importance of need for justice as a predictor of radicalization (e.g. Doosje et al., 2013; King \& Taylor, 2011; Mühlhausen, 2017; van den Bos, 2018; van den Bos, 2020). With respect to the quest for structure and purpose, striving to obtain justice for a group can clear up several big uncertainties about life.

In relation to this, perceived injustice and any experiences of discrimination and deprivation which may produce this feeling pertain to this theme. In our samples, interviewees rarely stated a generalized, persistent perception of injustice in their current 
society - in fact, in half of the instances of this code respondents explicitly stated that they experienced no injustice, as did this Muslim female interviewee:

[There are] these radical youths who think 'everyone is against us.' No, in Germany you have so many possibilities, more than you have in some Muslim countries. In Tunisia there used to be a headscarf-prohibition. In Turkey, you were not allowed to study at the university with your headscarf, in Turkey! Sometimes, we have so many rights in Germany, so many opportunities, so much support and the German state spends so much money on projects and you really just have to make use of them. (S1P1, line 4134)

Alongside describing that she did not feel unjustly treated in Germany, she also emphasized that the international comparisons frequently employed by radical groups' advertisements are often false. The experts placed more emphasis on this factor and drew connections to realistic or symbolic threat perceptions, as illustrated by this expert's statement:

What I hear, what I get from the right-wing extremists is xenophobia, a groupbased hatred against people. What I hear about are the Maghreb states, the refugees from Afghanistan, from Syria, those are who the right-wing extremists are focused on, 'they rape German women' and all that nonsense, of course. 'They get money from the state they don't deserve, and my grandmother doesn't get that', even though - those are the classic stereotypes being perpetuated, and on the internet, they spread nonstop. (S2P6, line164)

This illustrates the emphasis on perception: When it comes to threat, it can be just as potent a factor in radicalization when it is merely imagined as when it is real. 


\section{Themes in Deradicalization:}

\section{Improving Social Surroundings}

Cutting off destabilizing relations or relations within a radical group or forming new, stable and supportive social relations outside the radicalized scene is helpful in deradicalization. Several right-wing extremism experts stated that most of their clients were motivated by a need to belong and that they had many clients choosing to disengage after finding a stable romantic partner from outside the group, thus fulfilling their need to belong (e.g. S2P2, line 58; S2P7, line 120; S2P5, line 125). In contrast, radicalIslamism-expert S2P1 (line 266) observed: “(...) wanting to deradicalize because of true love, that hardly ever happens. Reasons are usually more egotistical".

Having a harmful social environment and cutting social bonds outside the group during the radicalization process cause the person to be bound more tightly to the group (now their only ingroup) and cause problems during disengagement due to loneliness or continuously being drawn back in. Hence, exit programs focus on changing the person's social environment, e.g. by tying their help to the condition of ending certain contacts or helping the person move somewhere new and start over (e.g. S2P1, line 162). In relation to this, experiences with discrimination and exclusion continue to be a problem during social reintegration - be it due to prejudice against the person's criminal convictions or due to their appearance giving away their past (e.g. S2P7, line 72).

In parallel to the theme of compensating for domestic problems in radicalization, the improvement of relationships with attachment figures can be central in deradicalization. A third of all descriptions of positive developments in the social environment given in Study 1 alone concerned the parents, indicating the key role attachment figures play in shaping vulnerability to radical ideologies. This was matched by a strong 
emphasis on attachment figures by right-wing extremism expert S2P7 (line 183), who perceived father figures as a pivotal factor in most of his cases.

\section{Experiencing Acceptance and Inclusion}

Radical groups often argue that they offer community to people rejected by the majority society. Thus, when a person experiences acceptance and inclusion outside the radical group, the group can lose its appeal, making it easier for the person to disengage. An example of such positive experiences was given by a female Muslim convert who wears a full face-veil (niqab):

It has to be said, most people in Germany are completely okay. Most people really have no problem with it. (...) Once I was filming in [city] with [German TV station] and they really wanted to hear all the insults from the people there. We had to walk through [city] for hours and talk to people until we heard some negative opinions, because most people said 'I have no problem with it' [the interviewee's face veil]. (S1P3, line 2345)

This interviewee's experiences of acceptance of her choice to wear the religious face veil positively shaped her relationship with and perception of German society. Of course, it is noteworthy that this person grew up in Germany and was socialised as a member of the majority religious community (Christian) and only converted to Islam in her early adulthood. Therefore, the basis for her relationship to German majority society and how "being German" fits into her identity is different from that of someone who immigrated to Germany and has a longer history of being "othered" by majority members. Still, from her statement that "they really wanted to hear all the insults", it is apparent that the filming crew and possibly she herself went into the project expecting a negative intergroup experience and strong exclusion. To have such a clear expectation decisively disproven and be met with overwhelming acceptance instead was certainly beneficial for her. 


\section{Improving Personal Status and Self-Image}

There was a particular focus on the experts' part on generating experiences of professional, academic or similar success - e.g. finding a job, pursuing further education, or even volunteering somewhere - which can boost their clients' self-image and thus make them less dependent on the false sense of status membership in a radical group can give them. Notably, this corresponded to a report from the one male interviewee in Study 1, who recounted leaving Salafist circles after finding a job:

He is my boss today. He helped me so much. But, the only condition he had was, he told me I could no longer be in contact with Pierre Vogel and so on, because he didn't want that at all. On the one hand, I understood, on the other hand, I didn't. But I did it, even though it was hard, because like I said, they had helped me before. I was always grateful to them and always will be. (S1P4, line 431)

By "they had helped me before", he was referring to an earlier part of the interview in which he described that he became responsible for his younger siblings at a young age after his parents were arrested for drug-related offences. He described rejecting help from the Social Services and Child Protective Services out of pride and, as a consequence, coming under great financial strain, at which point the Salafist group around Pierre Vogel effectively supported him by providing groceries. However, his new-found employment resolved these problems and enabled him to regain a better position in life. He complied with his employer's wish to break off these contacts out of gratitude. At the same time, being able to earn money and provide for his family by his own efforts improved his social status, which had previously been lowered by being perceived as dependent on help. 


\section{Finding Structure and Stability}

Providing structure and stability in day-to-day life can end susceptibility to radical groups, which often offer clear and simple structures to those who are lost and disoriented. One right-wing-extremism expert described how he utilizes means of providing stability in his work to support those particularly seeking out structure: “... with a pure follower-type, it's very important to give him stability, and to replace the group by that - that works very well" (Interview S2P2, line 86). Notably, while some experts spoke about providing structure, as did this interviewee, they did not describe providing a sense of existential meaning in the same way. This might be because it is much more difficult to give someone meaning, or because what ultimately will create meaning in a person's life is something deeply personal that has to be discovered of one's own accord.

\section{Disillusionment and Maturing Out}

Among those who do disengage from radical groups, disillusionment is a very common experience. While any number of factors may culminate, and while it may happen gradually or suddenly, eventually they result in the realization that the extremist ideas or groups the person has been engaging with are not serving the expected purpose, that is, do not fulfil the needs intended to fulfil (anymore), or they are violating other pivotal needs. This can occur as a simple result of needs and priorities changing as a person grows up, in which case it is referred to as "maturing out" (S2P6, line 91). The average age of disengagement was placed around the mid to late 20s by our experts (S2P7, line 120; S2P2, line 102; ibid., line 110), because around this time many people notice that the path they are following is going nowhere (S2P2, line 102). Once this time window closes, one expert deems deradicalization unlikely: "Our experience is this: if someone remains in the right-wing extremist scene until the age of 30 , and 
they shape their life around this, it is unlikely that they will leave the scene after that" (S2P2, line 118).

It can also be triggered by concrete, external events. For example, one interviewee (S1P3) enjoyed the online sermons on Pierre Vogel's YouTube channel, but was so disappointed in the way his followers behaved that she distanced herself from the group. It can also occur more internally: Another female interviewee who converted to Islam (S1P2) described disillusionment with the state of her own knowledge, from which a connection can be drawn to recent research conceptualizing monopoly on truth as a key cognitive component of radicalization (Dono et al., 2018). That is, radical groups commonly market their views as irrefutable truths which are entirely resilient against criticism or outside arguments - a belief which people adapt to varying degrees as they radicalize. Thus, the realization that her own knowledge about Islam was far from as complete and correct as she had assumed induced disillusionment in this interviewee. Another interesting factor which can induce disillusionment cited by one of the experts was intergroup contact: “(...) for example, maybe I think 'all foreigners suck', but my neighbour Mohammed, he's okay - these contradictions pile up" (S2P3, line 50). This ties in with the long line of research on intergroup contact theory which has put forward substantial evidence that positive quality contact with outgroup members diminishes intergroup bias and prejudice (Pettigrew \& Tropp, 2006).

When such a moment of disillusionment occurs, it allows the person to gain distance from their own radicalization process and look at it from a new perspective:

(...) it's part of the process, if it happens eventually that you feel disappointed in your brothers, that you feel betrayed, that you notice 'okay, this all hasn't been quite what it was promised to be. No loyalty, no sticking together'. In other words, if you're disappointed - disillusioned - ultimately, that can make you question yourself and your behaviour. And as you're questioning everything, 
you realize 'what's this group ever actually done for me, and what negative things has it brought me?' (S2P4, line 120)

Deradicalization counsellors will attempt to induce disillusionment by utilizing their clients' personal life goals (S2P5, line 121).

\section{Discussion}

We conducted a small-scale, two-part interview study, taking advantage of different data sources, in order to explore which root factors are common to both radicalization and deradicalization and how they manifest. In Study 1, we analysed first-hand data from participants who had disengaged in the early stages of radicalization, while in Study 2, we collected second-hand data from professionals in the field of deradicalization- and disengagement-support.

We employed an extensive set of theory-based and inductively created codes, some of which we then collated into overarching themes. We identified five meaningful themes connected to radicalization: compensating for domestic and social problems, experiencing and compensating for exclusion, constructing facets of social identity, improving personal status, and seeking out purpose and existential meaning. We also identified five meaningful themes connected to deradicalization: improving social surroundings, experiencing acceptance and inclusion, improving personal status and selfimage, finding structure and stability, and disillusionment and maturing out.

\section{Limitations}

The study's small and specific sample and generally explorative direction naturally prohibit generalizations drawn from our results. Locally, our results cannot be separated from the context of Germany (different regions of Germany were represented in the sample). Typologically, all tentative conclusions are limited to individuals who eventually do disengage/deradicalize. Different patterns of factors may be at work during radicalization for people who remain radicalized than for those who can eventually 
disengage. Our sample in Study 1 was also very particular because it was mostly female (four out of five interviewees), which is very unusual given that radicalization and ideologically motivated crime are a predominantly male issue (see, for example, the German annual prosecution statistics (Statistisches Bundesamt, 2019, p. 28) ${ }^{1}$ ), and because it only included religious (Islamist) extremism. In Study 2, our sample was skewed by self-selection bias: The experts were likely the most open and self-reflective members in their organisations, while their organisations, in turn, were likely more transparent and equipped with better resources than those who declined (e.g. for lack of time or hesitation to report seemingly insufficient results).

There are other limitations to both data sets which offset each other to some extent: In Study 1 first-hand data from the population of interest were collected, which means direct access to relevant information. However, there are cognitive biases inherent in retrospective data, such as omitting, adjusting and over- or under-stating some facts. A narrative changes over time, whether it is being told to others or to oneself, and this is difficult to reflect for interviewees. In contrast, the expert interviews in Study 2 provided less personal accounts which were perhaps less affected by repeated reflection and narrative adaptations, but at the cost of having only second-hand data which may lack insight into certain aspects. Moreover, the experts' personal biases, shaped by their identities, beliefs and life experiences, are inextricably linked with their perceptions of their clients, which shapes the data collected from them.

Other limitations concern the methods of data collection and interpretation: Firstly, the narrative interviews in Study 1 provided to us for secondary analysis by another (sociological) research team were not specifically targeted at our research

\footnotetext{
${ }^{1}$ Articles 129 a to 130 Par. 4 of the German Penal Code are various ideologically motivated crimes; note that in the Criminal Prosecution Statistics referenced here, the rows marked with $i$ stand for the total number of crimes and the rows marked with $m$ for the number of crimes committed by males. The statistics show that all of these ideologically motivated crimes were committed by mostly men.
} 
questions and produced a different kind of data than our own Study 2. Secondly, our measure of interrater-reliability was limited to an overlap percentage (for reasons explained above), which is not a statistically ideal measure for interrater-reliability.

\section{Parallels in Radicalization and Deradicalization: Themes}

Combining various root factors, we constructed five themes pertaining to radicalization and deradicalization, respectively, which were not identical, but parallel in several ways. Compensating for domestic and social problems during radicalization is paralleled by improving social surroundings during deradicalization, experiences of exclusion obviously parallel experiences of inclusion, constructing facets of social identity and improving personal status are paralleled by improving personal status and selfimage, and finally, seeking out a sense of purpose and existential meaning is, to some degree, paralleled by finding structure and stability. This parallel, however, is not perfect; from the accounts we received from our interviewees, it seems that definitively finding existential meaning is not necessary in order to begin disengagement and deradicalization. This search is a gradual process and can take place in parallel to and after disengagement, provided the conditions are met to make this possible. Finally, disillusionment and maturing out was a pivotal deradicalization theme.

These results are overall in line with radicalization literature highlighting the central role of uncertainty and the quest for significance and definition as a motivator (e.g. Van den Bos, 2018; Dugas \& Kruglanski, 2014), as well as with early findings on the central role of the need to belong as a motive (e.g. Baumeister et al., 2007; Baumeister \& Leary, 1995). The combination of need to belong and personal uncertainty in the "constructing facets of social identity" them is also in line with Social Identity Theory (cf. Tajfel \& Turner, 1986; Tajfel \& Turner, 1979).

This pattern of results is in line with another recent article which similarly combined data on the early and more advanced stages of radicalization: Pfundmair et al. 
(2019) identified as crucial factors in the process of radicalization the personal needs for transcendence, significance and control, which correspond to our themes of "seeking out a sense of purpose, existential meaning" and "improving personal status", as well as various group cohesion processes which correspond to our themes of "compensating for exclusion" and "constructing facets of social identity". These parallels are notable as they indicate the robustness of our findings despite the clear limitations of our samples.

\section{Parallels in Data Sources: First-Hand and Second-Hand}

Most root factors proved important in both studies and the construction of the themes from them was equally plausible, demonstrating substantial overlap between first-hand and second-hand data. Nonetheless, we observed differences concerning individual factors: Experts gave less space to the need for existential meaning in their narratives than did the formers in Study 2. For other factors, the groups disagreed on the direction of a factor's effect (for example, the experts were much more convinced of the positive effects of confrontations with public authorities and imprisonment than the formers). We suspect that such differences in focus are, on the part of the formers, due to social desirability and stigma hindering them from admitting to certain things (need for status, mental health issues) and, on the part of the experts, due to an inclination to focus on factors they can practically target with their exit programmes (professional perspectives, exposure to propaganda and radical people, exposure to a harmful social environment, negative experiences with authorities) and due to a lack of access to more abstract, private factors (ingroup identification).

Differences may also be due to Study 1 focusing on the early stages of the radicalization process of the formers, while the experts in Study 2 had more insight into the later stages. For example, negative experiences with authorities were ascribed a 
clearly negative influence by formers, often overlapping with experiences of discrimination and producing negative feelings towards the state and society. This can fuel feelings of relative deprivation, a factor considered key in the early phases of radicalization (e.g., Moghaddam, 2005). By contrast, the experts ascribed a positive influence to negative experiences with authorities, perceiving them as one of the main triggers of people's motivation to disengage.

\section{The Specifics of Female Religious Radicalization and Early Disengagement}

The sample of Study 1 was particular, in that four out of five interviewees were female and all of them had engaged with religious extremism before disengaging early on. A tentative comparison of religious and political types of radicalization leads us to suggest that the unique individual motivational configuration is key. Which motives are pivotal to a person determine to which radical group or ideology they are more likely to feel attracted, but they also determine the influence of risk, trigger and protective factors by making certain factors more salient than others. The experts we interviewed overall agreed that right-wing extremists are most frequently motivated by a need to belong or a need for status rather than an actual strong belief in their ideology; they agreed that in search of fulfilment of these needs, the radical group is basically interchangeable. They also described this group as frequently coming from broken families and suffering from disadvantages in terms of intelligence and education, resulting in low self-esteem which they seek to compensate by increasing their status elsewhere. Interestingly, right-wing extremists were described as particularly likely to have their deradicalization triggered by a new romantic partner, which, as a form of positive development in the social environment, also speaks to their need to belong.

By contrast, our explorers of religious extremism in Study 1 were more focused on the search for structure and for purpose. The one male interviewee also described his affiliation with a Salafist radical group as a strong boost for his social status - the 
group members were "like celebrities" to him and he thought of the Muslim identity as being like a superhero since his early childhood. Therefore, aligning himself with the radical group made him feel stronger, more powerful and more important. The female interviewees were overall more focused on clear answers, structure, and in a way peace; one interviewee explained that Islam held an answer for everything and no question in life was left open, something which no other religion could offer. Fully subscribing to such a system of rules and axioms can be a great source of peace and comfort, both on a mundane and an existential level.

They also differed in their descriptions of disengagement and deradicalization. The male explorer of religious extremism disengaged after his life conditions changed, relieving him from economic pressure (he found a new job he was very happy with) and enabling him to improve his social status and self-image (he could provide for his family and no longer felt like he was dependent on help). This is also in line with many of the experts' descriptions of what they focus on when supporting disengagement from various groups: They change their circumstances to make them a part of society, and the change of ideas follows. In contrast, when the female explorers of religious extremism explained what made them turn away from the radical community they had been interested in, their reasons were more cognitive: They described disillusionment with the community they had joined - being put off by other members' behaviour or starting to doubt ideological postulates - or, in one case, disillusionment with the state of their own knowledge. Radical groups typically operate on the assumption that they hold a monopoly on truth, and they give members a sense of power and security by convincing them that they will share this knowledge so that no questions will be left unanswered. This interviewee, however, described that as the group was trying to convince her of supposedly clear and unambiguous postulates of Islam, she realized that 
she knew far less than she had thought and that she had underestimated the complexities of religion. This personal disillusionment caused her to step away from providers of clear and simple answers and to spend more time studying and questioning religious principles.

Importantly in the German context, there are differences in the stigmatization experienced after disengagement. Former left-wing extremists face few obstacles and social resentment when trying to return into the centre of society, while former rightwing extremists are considerably more stigmatized, as one of the experts explained (S2P7, line 132). Another expert explained that former Islamist extremists face equally grave stigmatization, in particular if they have a criminal record for terrorist acts (S2P1, line 34). These differences in stigma are an important factor in the deradicalizationprocess and must be addressed by exit-programmes. It is helpful to distinguish, as suggested by Demant et al., 2008, between normative factors (the ideological reappraisal that takes place during deradicalization), and affective and continuance factors (the social stabilization and reintegration that is required to maintain the deradicalized and disengaged state). Both Demant et al. and interviewee S2P3 in our study warn that the affective component seems to frequently be neglected in deradicalization programmes.

\section{Conclusion}

We had a small and very particular, but also particularly interesting data set at our disposition. Female explorers of (religious) radicalization are not frequently the focus of empirical works (see, for example, Hoyle et al., 2015); violent extremism is predominantly a male issue, and since the focus in research is often on violent extremism, female interviewees are difficult to find. Our sample is not only interesting from this gender perspective, but also in terms of timing: While the fascination with radicalization in its ultimate, escalated stage, violent extremism, is understandable, it is the study of 
those who deradicalize or disengage early on that is more likely to give us ideas about how deradicalization takes place in most cases, how it can be supported and how radicalization might even be prevented. After all, most people who explore radical ideologies at some point never end up turning to violence.

There was overall agreement between the experts and the formers that social status and the life conditions that contribute to it (academic success, employment, economic strain etc.), the social implications of domestic problems, exclusion and discrimination versus inclusion, acceptance and improved social surroundings, identity definition and clear structures and the search for a sense of purpose and meaning were key themes in (de-)radicalization processes regardless of the ideological direction. Interestingly, we observed differences in deradicalization between our one male explorer of religious extremism, whose narrative was very focused on social status and tangible changes in life conditions (economic conditions, employment), and our female explorers of religious extremism, whose prompts for deradicalization were more cognitive and self-conscious, all centring around disillusionment and questioning pillars of the ideology.

The deradicalization experts informed us that they typically help their clients change their life circumstances - they motivate them to cut off contacts within the scene, they help them find employment, a new apartment if needed, and they encourage them to find new free-time activities where they can make new non-radicalized friends. They reported that these tangible measures were very helpful to their clients, and looking at the interviews from Study 1, it seems that such assistance could have prevented our one male interviewee from making contact with the radical group he associated with for a while. In his narrative, he stated that he turned to religion the day his parents were arrested for drug trafficking, and he became aware of the group he would later join soon after. It is unclear whether his parents' criminal activities were 
related to economic strain and could thus have been prevented by the social system; however, had there been financial and psychosocial assistance available to him and his siblings after their arrest that he had felt comfortable accepting - he stated that he was too proud to accept such help from the State - he might not have felt drawn to the group in the first place.

But what about the female explorers of religious extremism? There are tangible support programs that could have improved their lives; for example, one reported prolonged traumatic bullying during her childhood, another reported great difficulties on the labour market and experiences of discrimination due to her religious attire. Antibullying programmes at school, targeted labour-market initiatives which focus on supporting minorities entering the labour market, and anti-discrimination initiatives could have improved their quality of life. However, based on their narratives, it is not clear this would have affected their (de-)radicalization; while they described these experiences and events as difficult and, in a way, making them vulnerable, in their explanations of how they came to explore these ideologies they focused more on wanting structure, wanting someone to provide clear, simple rules and unambiguous explanations, and in some cases, being on a more general quest for purpose and meaning in life. Correspondingly, their focus in deradicalization was not on changing life conditions, but on cognitive factors: disillusionment, questioning whether a group really way what it claimed to be, whether ideological axioms were really true and even whether their own knowledge really was what they thought. So, if not the typical intervention and prevention measures, what would these interviewees have needed in terms of support to prevent them from exploring these radical ideologies and/or to assist their disengagement? Arguably, nothing. They were equipped with the skill of critical thinking, the self-confidence to question the axioms of the new ideology they were interested in, and the self-reflectiveness to recognize gaps in their own knowledge. Their 
search for existential meaning and stability and structure in their life was both fundamentally human and legitimate; they encountered radical ideologies and communities, explored them, evaluated them with their cognitive skills and discarded them before becoming involved more seriously upon finding that they were not what would fulfil their needs. An exploration that takes such a course and therefore results in harm to no one is not inherently problematic.

What remains, then, is a question worth exploring in future studies: Is this, perhaps, the difference between those who disengage/deradicalize early on and those who are dragged along by the group and need assistance in disengaging? Are these protective factors equally relevant to people with different central motives than seeking existential meaning and seeking structure and stability? Moreover, future studies should utilize adolescent samples wherever possible. Interviewees in both studies described radicalization as something that begins in adolescence; yet virtually all studies are conducted with adults giving retrospective information which is therefore inherently biased. Surveying adolescent samples could eliminate this bias; moreover, longitudinal studies could investigate whether the factors that seemed protective among our female explorers of religious extremism are indeed related to earlier disengagement or even avoidance of exploration of radical ideologies. 


\section{References}

Barrelle, K. (2014). Pro-integration: Disengagement from and life after extremism. Behavioral Sciences of Terrorism and Political Aggression, 7(2), 129-142. doi:10.1080/19434472.2014.988165

Baugut, P., \& Neumann, K. (2019). Online propaganda use during Islamist radicalization. Information, Communication \& Society, 1-23. doi:10.1080/1369118X.2019.1594333

Baugut, P., \& Neumann, K. (2020). Online news media and propaganda influence on radicalized individuals: Findings from interviews with Islamist prisoners and former Islamists. New Media \& Society, 22(8), 1437-1461. doi:10.1177/1461444819879423

Baumeister, R. F., Brewer, L. E., Tice, D. M., \& Twenge, J. M. (2007). Thwarting the Need to Belong: Understanding the Interpersonal and Inner Effects of Social Exclusion. Social and Personality Psychology Compass, 1(1), 506-520. doi:10.1111/j.1751-9004.2007.00020.x

Baumeister, R. F., \& Leary, M. R. (1995). The Need to Belong: Desire for Interpersonal Attachments as a Fundamental Human Motivation. Psychological Bulletin(117(3)), 497-529.

Bélanger, J. J., Moyano, M., Muhammad, H., Richardson, L., Lafrenière, M. A. K., McCaffery, P., Framand, K. \& Nociti, N. (2019). Radicalization leading to violence: a test of the $3 \mathrm{~N}$ model. Frontiers in psychiatry, 10, 42. doi: 10.3389/fpsyt.2019.00042

Bjørgo, T. (2002). Exit neo-Nazism: Reducing recruitment and promoting disengagement from racist groups. Retrieved from: http://hdl.handle.net/11250/2394077 Bjørgo, T. (2011). Dreams and disillusionment: Engagement in and disengagement 
from militant extremist groups. Crime, Law and Social Change, 55(4), 277285. doi:10.1007/s10611-011-9282-9

Borum, R. (2003). Understanding the terrorist mind-set. FBI Law Enforcement Bulletin, July(72), 7-10.

Braun, V., \& Clarke, V. (2016). (Mis) conceptualising themes, thematic analysis, and other problems with Fugard and Potts'(2015) sample-size tool for thematic analysis. International Journal of social research methodology, 19(6), 739-743. doi: $10.1080 / 13645579.2016 .1195588$

Bubolz, B. F., \& Simi, P. (2015). Leaving the world of hate: Life-course transitions and self-change. American Behavioral Scientist, 59(12), 1588-1608. doi: $10.1177 / 0002764215588814$

Carter, S. M., \& Little, M. (2007). Justifying knowledge, justifying method, taking action: Epistemologies, methodologies, and methods in qualitative research. Qualitative health research, 17(10), 1316-1328. doi: $10.1177 / 1049732307306927$

Castano, E., Yzerbyt, V., Paladino, M.-P., \& Sacchi, S. (2002). I Belong, therefore, I Exist: In-group Identification, Ingroup Entitativity, and Ingroup Bias. Personality and Social Psychology Bulletin, 28, 135-143. doi:10.1177/0146167202282001

Cottee, S., \& Hayward, K. (2011). Terrorist (e) motives: The existential attractions of terrorism. Studies in Conflict \& Terrorism, 34(12), 963-986. doi: 10.1080/1057610X.2011.621116

Demant, F., Slootman, M., Buijs, F., \& Tillie, J. (2008). Decline and Disengagement: An Analysis of the Process of Deradicalization. IMES Amsterdam.

Della Porta, D., \& LaFree, G. (2012). Guest editorial: Processes of radicalization and de-radicalization. International Journal of Conflict and Violence, 6(1), 4-10. doi: $10.4119 / \mathrm{ijcv}-2926$ 
Dono, M., Alzate, M., Seoane, G., \& Sabucedo, J. M. (2018). Development and validation of the Monopoly on Truth Scale. A measure of political extremism. Psicothema, 30(3), 330-336. doi: 10.7334/psicothema2017.423

Doosje, B., Loseman, A., \& Van den Bos, K. (2013). Determinants of Radicalization of Islamic Youth in the Netherlands: Personal Uncertainty, Perceived Injustice, and Perceived Group Threat. Journal of Social Issues, 69(3), 586-604. doi:10.1111/josi.12030

Doosje, B., Moghaddam, F. M., Kruglanski, A. W., Wolf, A. de, Mann, L., \& Feddes, A. R. (2016). Terrorism, radicalization and de-radicalization. Current Opinion in Psychology, 11, 79-84. doi:10.1016/j.copsyc.2016.06.008

Doosje, B., Van den Bos, K., Loseman, A., Feddes, A. R., \& Mann, L. (2012). “My Ingroup is Superior!: ": Susceptibility for Radical Right-wing Attitudes and Behaviors in Dutch Youth. Negotiation and Conflict Management Research, 5(3), 253-268. doi:10.1111/j.1750-4716.2012.00099.x

Dugas, M., \& Kruglanski, A. W. (2014). The quest for significance model of radicalization: Implications for the management of terrorist detainees. Behavioral Sciences \& the Law, 32(3), 423-439. doi:10.1002/bsl.2122

Feddes, A. R., Nickolson, L., \& Doosje, B. (2015). Triggerfactoren in het radicaliseringsproces [Trigger Factors in the Radicalisation Process]. Amsterdam. Expertise-unit Sociale Stabiliteit, Universiteit van Amsterdam. https://pure.uva.nl/ws/files/2636988/172573_triggerfactoren_in_het_radicaliser ingsproces.pdf (last retrieved 09.08.2020).

Frounfelker, R. L., Frissen, T., Vanorio, I., Rousseau, C., \& d'Haenens, L. (2019). Exploring the discrimination-radicalization nexus: empirical evidence from youth and young adults in Belgium. International journal of public health, 64(6), 897-908. doi: 101007/s00038-019-01226-z 
Fuß, S., \& Karbach, U. (2014). Grundlagen der Transkription: Eine praktische Einführung (1. Aufl.) [Basics of transcription: A practical introduction (1st ed.)]. UTB: 4185 : Sozialwissenschaften.

Haggerty, K. D., \& Bucerius, S. M. (2020). Radicalization as martialization: Towards a better appreciation for the progression to violence. Terrorism and political violence, 32(4), 768-788. doi:10.1080/09546553.2017.1404455

Harris, K., Gringart, E., \& Drake, D. (2014, December 1 - 3). Understanding the role of social groups in radicalization [Conference proceeding]. 7th Australian Security and Intelligence Conference, Edith Cowan University, Perth, Western Australia. doi: 10.4225/75/57a83235c833d

Harris, K. J., Gringart, E., \& Drake, D. (2017). Leaving ideological groups behind: A model of disengagement. Behavioral Sciences of Terrorism and Political Aggression, 1-19. doi:10.1080/19434472.2017.1299782

Horgan, J., Altier, M. B., Shortland, N., \& Taylor, M. (2017). Walking away: the disengagement and de-radicalization of a violent right-wing extremist. Behavioral sciences of terrorism and political aggression, 9(2), 63-77. doi: 10.1080/19434472.2016.1156722

Hoyle, C., Bradford, A., \& Frenett, R. (2015). Becoming Mulan?: Female western migrants to ISIS. Institute for Strategic Dialogue.

King, M., \& Taylor, D. M. (2011). The Radicalization of Homegrown Jihadists: A Review of Theoretical Models and Social Psychological Evidence. Terrorism and Political Violence, 23(4), 602-622. doi:10.1080/09546553.2011.587064

Kruglanski, A. W., Chen, X., Dechesne, M., Fishman, S., \& Orehek, E. (2009). Fully Committed: Suicide Bombers' Motivation and the Quest for Personal Significance. Political Psychology, 30(3), 331-357. doi:10.1111/j.1467$9221.2009 .00698 . x$ 
Kruglanski, A. W., \& Fishman, S. (2009). Psychological Factors in Terrorism and Counterterrorism: Individual, Group, and Organizational Levels of Analysis. Social Issues and Policy Review, 3(1), 1-44. doi:10.1111/j.17512409.2009.01009.x

Kruglanski, A. W., Gelfand, M. J., Sheveland, A., Babush, M., Hetiarachchi, M., Ng Bonto, M., \& Gunaratna, R. (2016). What a difference two years make: Patterns of radicalization in a Philippine jail. Dynamics of asymmetric conflict, 9(13), 13-36. doi:10.1080/17467586.2016.1198042

Macdougall, A. I., van der Veen, J., Feddes, A. R., Nickolson, L. \& Doosje, B. (2018). Different Strokes for Different Folks: The Role of Psychological Needs and Other Risk Factors in Early Radicalisation. International Journal of Developmental Science, 12(1-2), 37-50. doi:10.3233/DEV-170232

McBride, M. K. (2011). The logic of terrorism: Existential anxiety, the search for meaning, and terrorist ideologies. Terrorism and political violence, 23(4), 560581. doi:10.1080/09546553.2011.575486

McCauley, C., \& Moskalenko, S. (2008). Mechanisms of Political Radicalization: Pathways Toward Terrorism. Terrorism and Political Violence, 20, 415-433. doi:10.1080/09546550802073367

Moghaddam, F. M. (2005). The staircase to terrorism: A psychological exploration. The American Psychologist, 60(2), 161-169. doi:10.1037/0003-066X.60.2.161

Morgan, D. H. (1987). Masculinity and violence. In Women, violence and social control (pp. 180-192). Palgrave Macmillan, London. doi: 10.1007/978-1-34918592-4_13

Mühlhausen, A. (2017). Conflict Management, Transitional Justice and De-radicalization - Different, but common goals. Journal for Deradicalization, (9), 260-291.

Nussio, E. (2020). The role of sensation seeking in violent armed group participation. 
Terrorism and political violence, 32(1), 1-19.

doi:10.1080/09546553.2017.1342633

Özerdem, A., \& Podder, S. (2011). Disarming youth combatants: Mitigating youth radicalization and violent extremism. Journal of Strategic Security, 4(4), 63-80. doi:10.5038/1944-0472.4.4.3

Pettigrew, T. F., \& Tropp, L. R. (2006). A meta-analytic test of intergroup contact theory. Journal of personality and social psychology, 90(5), 751-783. doi: $10.1037 / 0022-3514.90 .5 .751$

Pfundmair, M., ABmann, E., Kiver, B., Penzkofer, M., Scheuermeyer, A., Sust, L., \& Schmidt, H. (2019). Pathways toward Jihadism in Western Europe: An Empirical Exploration of a Comprehensive Model of Terrorist Radicalization. Terrorism and Political Violence, 1-23. doi:10.1080/09546553.2019.1663828

Reid, S. A., \& Hogg, M. A. (2005). Uncertainty reduction, self-enhancement, and ingroup identification. Personality and Social Psychology Bulletin, 31, 804-817. doi:10.1177/0146167204271708

Robinson, O. C. (2014). Sampling in interview-based qualitative research: A theoretical and practical guide. Qualitative Research in Psychology, 11(1), 2541. doi: $10.1080 / 14780887.2013 .801543$

Schils, N., \& Verhage, A. (2017). Understanding how and why young people enter radical or violent extremist groups. International Journal of Conflict and Violence, 11(2), 1-17. doi:10.4119/ijcv-3084

Schumpe, B. M., Bélanger, J. J., Moyano, M., \& Nisa, C. F. (2020). The role of sensation seeking in political violence: An extension of the Significance Quest Theory. Journal of Personality and Social Psychology, 118(4), 743-761. doi: 10.1037/pspp0000223

Sikkens, E., van San, M. R. P. J. R. S., Sieckelinck, S. M. A., \& de Winter, M. (2017). 
Parental Influence on Radicalization and De-radicalization according to the Lived Experiences of Former Extremists and their Families. Journal for Deradicalization, 12, 192-226.

Statistisches Bundesamt (2019). Strafverfolgungsstatistik 2018 [German Criminal Prosecution Statistics for 2018]. Fachserie 10, Reihe 3. https://www.destatis.de/DE/Themen/Staat/Justiz-Rechtspflege/Publikationen/DownloadsStrafverfolgung-Strafvollzug/strafverfolgung-2100300187004.pdf?_blob=publicationFile (last retrieved 03.10.2020).

Stephan, W. G., \& Stephan, C. W. (1985). Intergroup Anxiety. Journal of Social Issues, 41, 157-175. doi:10.1111/j.1540-4560.1985.tb01134.x

Tajeel, H., \& Turner, J. (1979 (reprinted 2004)). An Integrative Theory of Intergroup Conflict. In Organizational identity: A reader (pp. 56-65). Oxford University Press.

Tajfel, H., \& Turner, J. C. (1986 (reprinted 2004)). The Social Identity Theory of Intergroup Behavior. In Political Psychology - Key Readings (pp. 276-293). Psychology Press. doi:10.4324/9780203505984-16

Turner, R. N., Hewstone, M., \& Voci, A. (2007). Reducing explicit and implicit outgroup prejudice via direct and extended contact: The mediating role of self-disclosure and intergroup anxiety. Journal of Personality and Social Psychology, 93, 369-388. doi:10.1037/0022-3514.93.3.369

Turner, R. N., Hewstone, M., Voci, A., \& Vonofakou, C. (2008). A test of the extended intergroup contact hypothesis: The mediating role of intergroup anxiety, perceived ingroup and outgroup norms, and inclusion of the outgroup in the self. Journal of Personality and Social Psychology, 95, 843-860. doi:10.1037/a0011434

Van den Bos, K. (2018). Why people radicalize: How unfairness judgements are 
used to fuel radical beliefs, extremist behaviors, and terrorism. Perspectives on justice and morality. Oxford University Press.

doi:10.1093/oso/9780190657345.001.0001

Van den Bos, K. (2020). Injustice and violent extremism: Methodological directions for future justice research. In (2020) Lind, E. A. (ed.), Social psychology and justice, pp. 162 - 180. doi: 10.4324/9781003002291

Webber, D., \& Kruglanski, A. W. (2018). The social psychological makings of a terrorist. Current Opinion in Psychology, 19, 131-134.

doi:10.1016/j.copsyc.2017.03.024

Webber, D., Babush, M., Schori-Eyal, N., Vazeou-Nieuwenhuis, A., Hettiarachchi, M., Bélanger, J. J., Moyano, M., Trujillo, H. M., Gunaratna, R., Kruglanski, A. W., \& Gelfand, M. J. (2018). The road to extremism: Field and experimental evidence that significance loss-induced need for closure fosters radicalization. Journal of Personality and Social Psychology, 114(2), 270-285. doi:10.1037/pspi0000111

Winter, D. A., \& Feixas, G. (2019). Toward a constructivist model of radicalization and deradicalization: A conceptual and methodological proposal. Frontiers in psychology, 10, 412. doi: 10.3389/fpsyg.2019.00412 


\section{Tables}

\section{Table 1}

\section{Overview of Participants in Study 1}

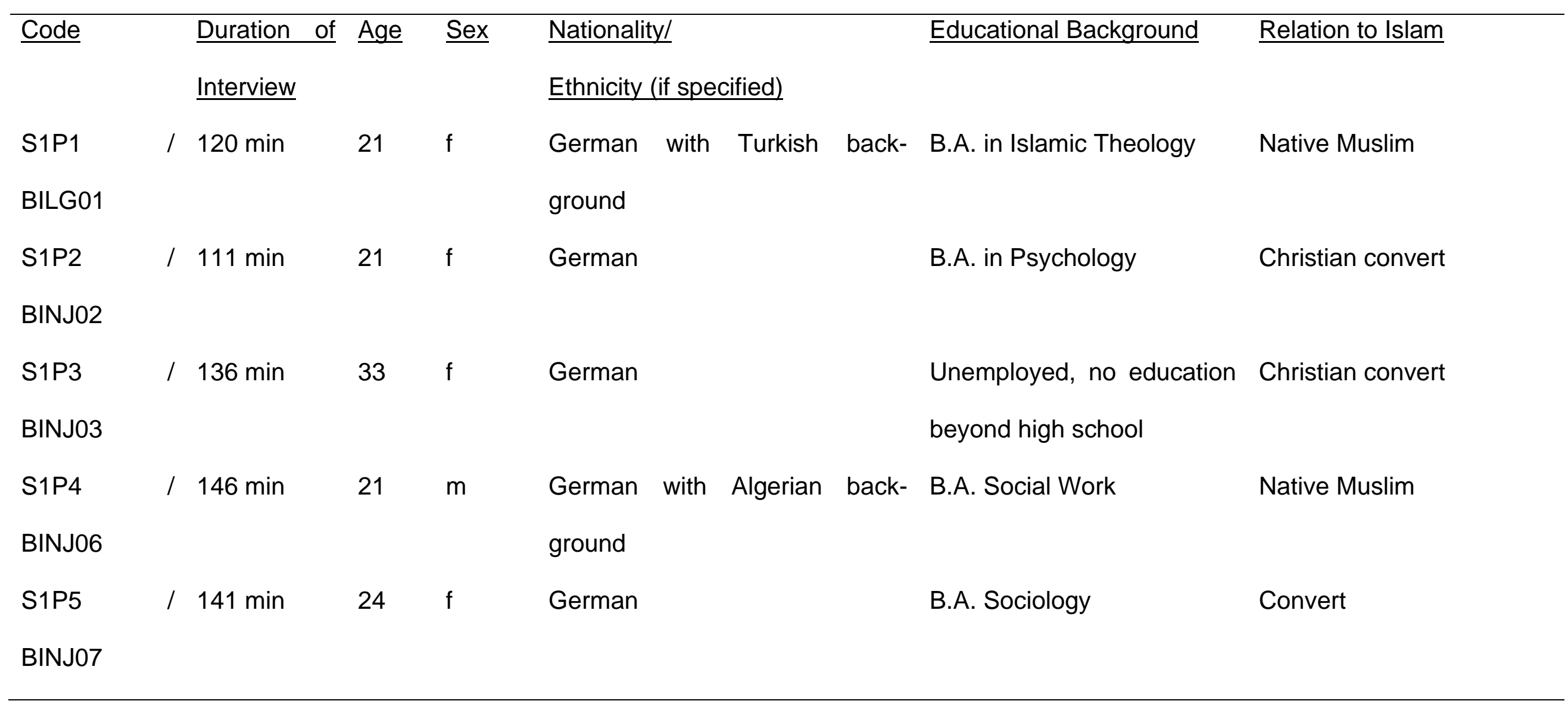




\section{Table 2}

Measures of Inter-Coder Agreement per Code, Calculated Before and After Discussion

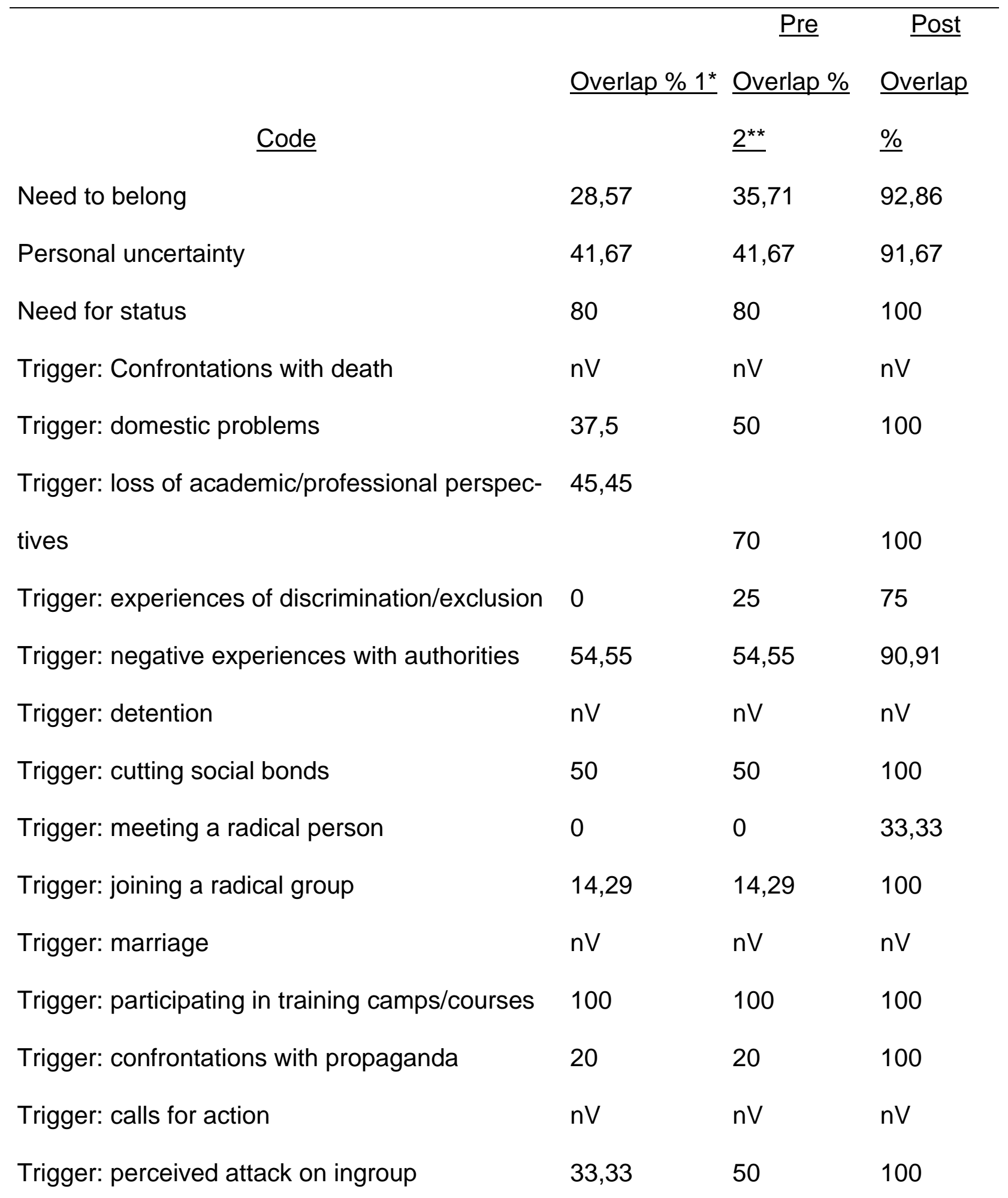


Trigger: policies directed at ingroup or radicali- 100

zation

50

50

Disillusionment

0

$\mathrm{nV}$

$\mathrm{nV}$

Risk Factor: perceived deprivation

33,33

33,33

100

Risk Factor: intergroup anxiety

0

$\mathrm{nV}$

$\mathrm{nV}$

Risk Factor: ingroup identification

0

40

100

Risk Factor: perceived threat

0

$\mathrm{nV}$

$\mathrm{nV}$

Risk Factor: perceived injustice

25

25

100

Risk Factor: mental health issues

$\mathrm{nV}$

$\mathrm{nV}$

$\mathrm{nV}$

Risk Factor: harmful social environment

28,57

44,44

100

Experiences of acceptance, inclusion

33,33

33,33

100

Positive developments of the social environment 5

50

47,83

95,65

Note. The table only presents a sub-set of the variables measured.

* Basis of calculation: number of agreements (each agreement is coded as 1, each disagreement as 0 ) divided by total number of codes (sum total of codes used by both coders is used).

${ }^{* *}$ After the first round of coding, coder B received additional explanations of a number of codes (specifically: "Discrimination", "Meeting a radical person", "Joining a radical group", and "Disillusionment") which they had not understood completely or correctly. Coder B then had the opportunity to re-evaluate their coding before discussion of the interview with coder A. The first two columns represent those two coding rounds. The column "Post Overlap", by contrast, presents results after the complete and final discussion of all codes.

"nV" stands for "no value" - this code did not appear anywhere and was correctly not coded by either of the coders. 
Table 3

Overview of Participants in Study 2, Including Information on Them, Their Programmes and Clients

\begin{tabular}{|c|c|c|c|c|c|c|c|c|}
\hline \multirow[t]{2}{*}{ Code } & \multicolumn{6}{|c|}{ Information on Participant \& Program } & \multicolumn{2}{|c|}{ Information on Clients } \\
\hline & $\frac{\text { Professional }}{\text { Background }}$ & $\underline{\text { Ideology }}{ }^{1}$ & $\begin{array}{c}\text { Time at } \\
\text { current job }\end{array}$ & $\frac{\text { Time in profes- }}{\underline{\text { sional field }}{ }^{2}}$ & $\begin{array}{l}\text { Duration } \\
\text { Interview }\end{array}$ & $\begin{array}{c}\text { Nr. clients } \\
\text { simultaneously }\end{array}$ & \% voluntarily 3 & $\frac{\text { Avg. duration }}{\text { of treatment }}$ \\
\hline $\begin{array}{l}\text { S2P1 / } \\
\mathrm{CH} 2707\end{array}$ & $\begin{array}{c}\text { Social worker / } \\
\text { pedagogue }\end{array}$ & 1 & $2 y$ & $10 y$ & 01:09:03 & 14 & 50 & $2-5 y$ \\
\hline $\begin{array}{l}\text { S2P2 / } \\
\text { BR1311 }\end{array}$ & $\begin{array}{c}\text { Police / homeland } \\
\text { security agent }\end{array}$ & $R / L$ & $3 y$ & $20 y$ & 01:01:09 & 9 & 100 & $3-5 y$ \\
\hline $\begin{array}{l}\text { S2P3 / } \\
\text { MK2105 }\end{array}$ & $\begin{array}{l}\text { Social peda- } \\
\text { gogue }\end{array}$ & $\mathrm{R}^{4}$ & $2 y$ & 28 y & $01: 14: 14$ & 13 & $\begin{array}{l}\text { "more than } \\
\text { involuntary" }\end{array}$ & $5 y$ \\
\hline $\begin{array}{l}\text { S2P4 / } \\
\text { BJ1903 }\end{array}$ & $\begin{array}{c}\text { Police / homeland } \\
\text { security agent }\end{array}$ & 1 & $2.5 \mathrm{y}$ & unknown & $01: 33: 40$ & 12 & unknown & unknown \\
\hline $\begin{array}{l}\mathrm{S} 2 \mathrm{P} 5^{5} / \\
\mathrm{RR} 2608\end{array}$ & $\begin{array}{c}\text { Social psycholo- } \\
\text { gist }\end{array}$ & $\mathrm{R}$ & $10 \mathrm{~m}$ & $10 \mathrm{~m}$ & $01: 02: 51$ & unknown & $\begin{array}{c}\text { "more invol- } \\
\text { untary" }\end{array}$ & unknown \\
\hline
\end{tabular}




\begin{tabular}{|c|c|c|c|c|c|c|c|c|}
\hline $\begin{array}{c}\text { S2P6 / } \\
\text { MK1428 }\end{array}$ & $\begin{array}{c}\text { Homeland secu- } \\
\text { rity agent }\end{array}$ & $\mathrm{R} / \mathrm{L}$ & $14.5 y$ & unknown & $01: 32: 22$ & 14 & $\begin{array}{l}\text { "slightly more } \\
\text { involuntary at } \\
\text { the moment" }\end{array}$ & unknown \\
\hline $\begin{array}{l}\text { S2P7 / } \\
\text { EJ1611 }\end{array}$ & $\begin{array}{c}\text { Police / homeland } \\
\text { security agent }\end{array}$ & $\mathrm{R}$ & $17.5 y$ & unknown & $02: 02: 56$ & 5 ("a handful”) & 100 & $3-5 y$ \\
\hline
\end{tabular}

Note. ${ }^{1} \mathrm{I}=$ Islamism, $\mathrm{R}=$ Right-Wing Extremism, $\mathrm{L}=$ Left-Wing Extremism

2 Work in roughly the same sector - e.g. interviewee 2.2 has been with his current deradicalization-programme for three years but has been a member of the police force for 20 years.

${ }^{3}$ To some extent, it has been clarified unanimously by all of the interviewees, all participants of the programmes have to be there "voluntarily" since their approaches don't include the option of working with people against their will. The question of percentage of voluntary participants here refers to how many of the participants get in touch with the programme themselves, as opposed to being sent there by a judge, a parole officer etc.

4 This person was not only responsible for right-wing extremism, but also for motorbike gangs, allowing her to draw comparisons between radical and non-radical group-based crime.

5 This person was the only one to work in a non-state-run programme. 


\section{Table 4}

Measures of Inter-Coder Agreement per Code, Calculated Before and After Discussion

\begin{tabular}{|c|c|c|}
\hline & $\underline{\text { Pre }}$ & Post \\
\hline$\underline{\text { Code }}$ & Overlap \%* & Overlap \% \\
\hline Need to belong & 35,71 & 86,67 \\
\hline Personal uncertainty & 50 & 100 \\
\hline Need for status & 40 & 80 \\
\hline Trigger: confrontations with death & 100 & 100 \\
\hline Trigger: domestic problems & 55,56 & 100 \\
\hline Trigger: loss of academic/professional perspectives & 40 & 100 \\
\hline Trigger: experiences of discrimination/exclusion & 50 & 100 \\
\hline Trigger: negative experiences with authorities & 42,86 & 100 \\
\hline Trigger: detention & 66,67 & 100 \\
\hline Trigger: cutting social bonds & 100 & 100 \\
\hline Trigger: meeting a radical person & 20 & 20 \\
\hline Trigger: joining a radical group & 37,50 & 62,50 \\
\hline Trigger: marriage & 33,33 & 100 \\
\hline Trigger: participating in training camps/courses & $\mathrm{nV}$ & $\mathrm{nV}$ \\
\hline Trigger: confrontations with propaganda & 80 & 100 \\
\hline Trigger: calls for action & $\mathrm{nV}$ & $\mathrm{nV}$ \\
\hline Trigger: perceived attack on ingroup & 100 & 100 \\
\hline Trigger: policies directed at ingroup or radicalization & $\mathrm{nV}$ & $\mathrm{nV}$ \\
\hline Disillusionment & 75 & 100 \\
\hline Experiences of acceptance, inclusion & 0 & 100 \\
\hline
\end{tabular}


Risk Factor: perceived deprivation

Risk Factor: intergroup anxiety

Risk Factor: ingroup identification

Risk Factor: perceived threat

Risk Factor: perceived injustice

Risk Factor: mental health issues

Risk Factor: harmful social environment

Positive developments of the social environment
$\mathrm{nV}$

0

80

0

50

40

20

12,50
$\mathrm{nV}$

$\mathrm{nV}$

100

50

100

100

100

100

$\overline{\text { Note. The table only presents a sub-set of the variables measured, selected according }}$ to relevance to the topic of this article.

* Basis of calculation: number of agreements (each agreement is coded as 1, each disagreement as 0 ) divided by total number of codes (sum total of codes used by both coders is used).

\section{Table 5}

\section{Summary and definitions of constructed themes}

\section{Themes in radicalization}

$\begin{array}{ll}\text { Compensating for domestic / social problems } & \text { Radical groups can offer stability and social } \\ & \text { structures to compensate for problems in the } \\ & \text { home life - e.g. crime-related instability, eco- } \\ & \text { nomic distress, absence of a stable parental re- } \\ & \text { lationship. }\end{array}$

Experiencing and compensating for exclusion Radical groups can present an opportunity for strong and stable social affiliation, which can be 
attractive to people experiencing continuous exclusion, discrimination and loneliness.

Constructing facets of social identity

Improving personal status
For those who are personally insecure and looking for an external criterion to define their identity, the affiliation with a radical group can be key in social identity construction; in other words, joining a radical group enables them to define who they are as whom they are surrounded by. When someone perceives their status as low, e.g. due to lack of professional success, academic perspectives, precarious socio-economic status, radical groups can offer ways to enhance their status. Taking on tasks in the group and participating in the fight for a cause can lift a person's status both in their own and others' eyes.

Seeking out a sense of purpose, existential In the search for a purpose in life, radical groups meaning can offer clear and simple answers; the ideology they pursue typically presents a goal of fundamental importance and clear implications regarding how to live in accordance with that goal.

\section{Themes in deradicalization}

Improving social surroundings

Cutting off destabilizing relations / relations with people within a radical group or forming new, stable and supportive social relations outside 
the radicalized scene is helpful in deradicalization and sustainable social reintegration.

Experiencing acceptance and inclusion

Improving personal status and self-image

Finding structure and stability

Disillusionment and Maturing Out
Experiences that make a person feel included in the majority society and allow them to identify with it can decrease their susceptibility to radical groups; these groups often argue that they offer community to people rejected by the majority society.

Experiences which improve perceived status, such as academic success, finding employment etc., can decrease the motivation to compensate for low status by joining a radical group.

Finding other elements which can provide structure and stability in day-to-day life, such as stable employment, can end susceptibility to a radical group which offers clear and simple structures.

After some time in a radical group, some people find that it no longer satisfies the needs that originally drew them into it, either because their needs change and they simply mature, or because they find the group and its ideology are not what they were supposed to be. 